\title{
Study on Reliability Design Technology of Electronic Communications
}

\section{Equipment}

\author{
Meifang Cai ${ }^{1}$ \\ ${ }^{1}$ Nanchang Institute of Technology, Nanchang, Jiang Xi, 330108 \\ 346591653@163.com
}

\section{KEYWORDS: Reliability Analysis; Electronic Communications; Quality Problem}

\begin{abstract}
With the continuous development of social progress and economic and cultural, of gradually entering the information age, in the new situation of rapid development of information technology, science and technology constantly updated, electronic communications equipment as advanced science and technology is increasingly being taken seriously. With the enhancement of electronic communications equipment and increasing human needs, product styles are becoming increasingly diverse, so they asked to improve the quality of electronic equipment products. In the process of technical reliability of electronic communications equipment analysis, there are many factors that could affect the reliability of electronic communication equipment, therefore, need to be analyzed relevant factors and proposed security measures to enhance the reliability of electronic communications equipment.
\end{abstract}

\section{Introduction}

Electronic communication equipment is high-profile emerging technology industries, whether it is the popularity of mobile phones, mobile phone or Apple's replacement fast, reflects the electronic communications equipment has become essential to people's daily life and work there. With the strengthening of competition in the electronic communications equipment, people as users of electronic communications equipment, the choice of electronic communication devices first consideration is reliability design technology electronic equipment. This is the basis for electronic components, starting from the device performance, stability, cooling system, maintenance, etc., the use of new design techniques to make electronic communication devices for performance, size, weight, etc. to achieve optimized to ensure its reliability the process of. Of course, the reliability of electronic communications equipment design is that it runs through the life course, it can ensure that electronic communications device during use quality, extend the service life of electronic communications equipment. With the new public demand for electronic communications equipment in support of science and technology, the electronic communication devices gradually reflect intelligent, versatile, easy and convenient features, potentially increasing the pressure on electronic communications equipment components, and only from many begin to accelerate design updates components, in order to further improve the reliability of electronic communications equipment.

In today's competition heating up, more and more attention to the quality of products the user, the electronic device manufacturers alone to reduce costs to gain market initiatives have been unlikely to solve the problem. Many factors affect product quality, product reliability in which to improve the quality played a significant role. Currently, many companies have from. To examine 
means to ensure product quality. This is because the content of the latter than the former has been greatly expanded and extended, and reliability is one of the important content. He stressed that the implementation of comprehensive management of the whole process is proposed. Reliability is designed, produced, managed out. The reliability of the technology is used into product design, to ensure the reliability of the product from the source to achieve the dual purpose of improving reliability and reducing development costs, thereby enhancing the market competitiveness of products. Many reliability design technology electronic devices include content. We can be considered from the following aspects: security reliability design technology, EMC design, thermal design and resistance to environmental design technology and software reliability design technology.

\section{Factors that Affect the Reliability of Electronic Communication Equipment}

In the process of electronic communication equipment reliability design analysis, we found that there are many factors that affect the reliability of electronic communications equipment, and factor of production conditions is one of them. For electronic communication devices, intelligent and multi-functional facilitation is an important reason for its continued development, and intelligent facilitation and multifunctional implementation through the product development process of continuous innovation and reforms. In the context of innovation and reform, the need to have a more capable electronic communication equipment manufactured complete good production system to ensure manufacture of electronic communications equipment through the test. And some manufacturers in the electronic communications equipment in the production process, does not have adequate production conditions, production conditions do not exist and complete production machines and other issues behind some manufacturers carried out under production conditions for electronic and incomplete production machines premise behind blind production of communications equipment, will not guarantee the quality of electronic communications equipment, electronic communications equipment led to the rapid development of the market are not favorable, and thus can not improve the reliability of electronic communication equipment itself.

Among the factors affect the reliability of electronic communications equipment, mechanical conditions are another important factor affect the reliability of electronic communications equipment. In humans the use of electronic communication devices during usual equipment damage, and damage to electronic components lose their function and effect, so that users can no longer normal use of electronic communications equipment. In fact, damage to electronic communications equipment, more time is due to the user's own causes, users do not care for their own electronic communications equipment, to be thrown away after use in the side, causing the water also, or electronic communication equipment and other wrestling loss problems, damage to electronic communications equipment is also unpredictable and things can not be avoided. In addition, users of electronic communications equipment in the process, due to some external factors on electronic communications equipment caused a great deal of shock and vibration, resulting in the electronic communications equipment within the electronic components due to vibration and impact damage, thereby losing its proper role, structure deformation of electronic components, metal objects damaged, and many other factors, will make the electronic communications equipment does not work properly, affecting the reliability of electronic communications equipment, reduce the life of electronic communications equipment, electronic communications equipment is not promoted progress and development of reliability design technology.

Electronic communication equipment belonging to high-end scientific and technological products, with high quality and durable, electronic communications equipment has good reliability 
design techniques. But even then the high quality of electronic communication and cannot resist the external environment inflicting damage. In the electronic communications device during use, the use of more than a certain number of years subject to significant trauma or the outside world, will inevitably create some problems, problems of electronic communication equipment reliability will be affected, telecommunications equipment skills and no longer have the effect had before, the development of electronic communications equipment reliability design technology has been extremely limited, it is not conducive to the progress and development of electronic communications equipment.

\section{Reliability Design Technology}

For users, the most concerned about is the availability of equipment; for electronic communication devices, commonly used indicators of reliability and maintainability performance indicators to quantitative requirements. Factors that affect device reliability indexes There are many, generally through the use of control components, derating design, simplified design, redundant design, and robust design, reliability design technology to protect and improve the reliability of the device.

Electronic communication equipment is mainly composed by the electronic components. Reliability of components, will directly affect the reliability of the device. Therefore, in order to ensure the reliability of electronic communications equipment, reducing varieties and specifications of components, the correct selection and rational use of components, reduce overall security costs and life cycle costs of the components must be controlled. To ensure the reliability of components used, the equipment must be developed, the various stages of production and use to select components, procurement, producer, inspection, screening, storage, storage and use of the whole process of selection of the implementation of effective quality and reliability management.

Derating design is to make the components work or electronic equipment when subjected to an appropriate work stress less than the rated component or electronic device, which can reduce substantially the failure rate and improve the reliability purposes. Reliability of electronic communications equipment for the electrical and temperature stresses more sensitive, so derating becomes more prominent, technology is essential to the reliability of the design.

Derating is focused on the design of electronic components. For all types of electronic components, has its obvious derating range, in this range of work stress has its obvious failure rate effects, the design is also relatively easy to implement, and does not in equipment size, weight costs and paid a high price. Within the optimal derating range, generally can be divided into Class I, 11, and 1113 rating (which, $\mathrm{I}$ is the largest class deratin. $\mathrm{N}$ derating level of reliability growth has significant effects. 111 derating Although the role of insufficient reliability growth significantly, but the lowest cost, the design is also the easiest to implement in an electronic communication devices generally use n-level derating design technology, reliability of the equipment is only high and equipment failure will result in casualties or serious damage if the device uses a class I derating design techniques.

As it can be seen from the basic reliability of the model system, the greater the number of units of the device, the lower the reliability of the device. Thus, to ensure equipment performance requirements of the premise, as far as possible to make the design simplistic device and uses simplified design. At the same time improving the reliability, a simplified design can also reduce equipment maintenance.

Redundancy (redundancy) device is designed to obtain a highly reliable design of the more commonly used methods. Refers to devices with more than one set to complete a given functional 
unit, only when a predetermined unit sets are faulty device will be loss of function, so that the task of improving the reliability of the device. But redundancy design makes complex equipment, weight, cost and volume increases, so the basic reliability of the device is reduced. Higher when engineering experience that only when using better components and simplified design, reducing the amount of design and other technical equipment are unable to meet reliability requirements, or to improve the cost components than equipment using redundant technology costs before using redundancy design techniques.

The so-called robust design is to make the performance of the equipment to variation during manufacture or use of the environment variation insensitive, and the equipment in its life cycle, regardless of its parameters, structure, drift or aging (within certain limits), can be sustained satisfaction a design technique to work.

Robust design is developed on the basis of Taguchi method, seek a low-cost and high stability system optimization design method. Its guiding principle is to user needs traction, using Quality Function Deployment (QFD), three design methods carefully optimized design, to solve the problems at the design stage, in order to minimize the cost to obtain a high stability, ie, robust products. QFD weighted scoring method, the importance of design, technology and other requirements to make assessment, identify the key components of the product, the key processes, which pointed out the direction for the design of the three carried out. A complete quality function deployment includes four stages of product planning, parts planning, process planning and production planning. Three design refers to the system design, parameter design and tolerance design. In addition, FMEA, FTA, WCCA and DOE are all important ways to achieve robust design.

\section{Conclusion}

With the continuous development of social progress and economic and cultural, of gradually entering the information age, information technology in the rapid development of science and technology constantly updated new situation, electronic communications equipment as advanced science and technology is increasingly being taken seriously. Due to the use of electronic communication equipment increased, the product style is becoming more diverse, the quality of electronic communications equipment is particularly valued. In real life, there are still many factors that affect the reliability of electronic communications equipment design technology, the existence of the factors were analyzed and proposed solutions to keep opposing promote the development of electronic communication equipment reliability design technology.

\section{REFERENCE:}

[1] Zhou Jue. Reliability Design Technology of Electronic Communications Equipment [J]. Communication World, 2015.

[2] Chen Xu. Talking About the Reliability of Electronic Communications Equipment Design Analysis [J]. Information and Communications, 2013.

[3] Flexor Static Reliability Analysis of Electronic Communications Equipment Design [J]. Technology Rich Wizard, 2014.

[4] Luting Xiao, Zheng Pengzhou. Reliability Design and Analysis [M]. Beijing: Defense Industry Press, 1999.

. [5] Zhao Ting. Cross Electronics Thermal Control Technology [M]. Xi'an: Xi'an University of Electronic Science And Technology, 2000. 